MENTAL

HEALTH LAW PROFILE

\title{
Mental health law in Cyprus
}

\author{
Eleni Palazidou ${ }^{1,2}$ and Anna Polyniki ${ }^{1}$
}

\begin{abstract}
${ }^{1}$ St George's, University of London Medical Programme Delivered in Cyprus by the University of Nicosia Medical School, Engomi, Nicosia, Cyprus, Email: eleni.palazidou@doctors. org.uk

${ }^{2}$ Barts and The London School of Medicine and Dentistry and Wolfson Institute of Preventive Wedicine Queen Mar Unive Medicine University of London, London, UK

Acknowledgments. We thank Dr Charalambos Papadopoulos, President, and Mr Andreas Agrotis, ex-members of the MHC for clarifying some of the issues concerning the Mental Health Law and the role of the MHC.

Conflicts of interest: None.

doi:10.1192/bji.2017.24

(c) The Authors 2018. This is an Open Access article, distributed under the terms of the Creative Commons Attribution-

NonCommercial-NoDerivatives licence (http://creativecommons. org/licenses/by-nc-nd/4.0/), which permits non-commercial re-use, distribution, and reproduction in distribution, and reproduction in any medium, provided the original work is unaltered and is properly cited. The written permission of Cambridge University Press must be obtained for commercial re-use or in order to create a derivative work.
\end{abstract}

The current Law for Psychiatric Care in the Republic of Cyprus was enacted in 1997 with amendments made in 2003 and 2007. The mental health law makes provision for the development and function of Psychiatric Centres for the care of the mentally ill. In contrast to the old Mental Health Law there is a major shift from a custodial approach to community care. Compulsory admissions under the Act, which require a Court Order, are made to a designated secure psychiatric inpatient unit. The protection of patients' human rights is at the core of the Act.

The Mental Health Commission, a Supervisory Committee and designated body for the Protection of the Rights of the Mentally III, assists in the correct implementation of the Mental Health Law. The Commission has a primarily advisory role but it is actively involved in monitoring the implementation of the Mental Health Law.

Cyprus is the third largest Mediterranean island after Sicily and Sardinia. A member of the European Union and the Eurozone since 2004, and in the high-income category (World Bank, 2017), it has a population of 879723 . The population is predominantly Greek (78\%), with $18 \%$ Turkish and 4\% Christian Armenian, Maronite and Latin (Catholic) and other European minorities. The life expectancy at birth is 78.3 years for men and 82.7 for women (WHO, 2015). Neuropsychiatric conditions are estimated to contribute to $24.2 \%$ of the global burden of disease. The suicide rate is 7.4 per 100000 for men and 1.7 per 100000 for women (WHO, 2008), the lowest rate in Europe, although this may have climbed since the economic crisis of 2011.

\section{Brief relevant historical issues}

The history of Cyprus spans more than 10000 years. In 1974, a coup against the legitimate government of Cyprus, instigated by the then military dictatorship in Greece, was immediately followed by a Turkish invasion of the island. The Greek and Turkish communities were forcibly displaced and kept apart in two geographically separate zones. The Turkish army is still occupying $38 \%$ of the island, defying repeated United Nations resolutions.
The recent historical events and the continuing situation of a country divided by force, with displacement, loss of family, friends and property, and uncertainty as to what the future holds, are a major source of stress for all Cypriots.

\section{Mental health policy}

The Ministry of Health for Cyprus is currently in the process of reorganising healthcare, including mental health. The Council of Ministers has overall responsibility for the state's role in the social protection and healthcare system.

There is an officially approved mental health policy, and mental health is specifically mentioned in the general health policy. It should be noted that, although the mental health policy applies to the whole of the island of Cyprus, its implementation is not possible in the areas occupied by the Turkish army.

\section{Mental health law}

The Law for Psychiatric Care was enacted in 1997 (The Psychiatric Nursing Act, 1997), with amendments made in 2003 and 2007. It aims to make provision for the development and function of psychiatric centres for 'the care of the mentally ill, the safeguarding of the rights of these people and the specification of the duties and responsibilities of the relatives'. This replaces the 1931 Mental Patients Law relating to the 'Custody and Maintenance of Mental Patients, Criminal Mental Patients and Insane Prisoners and the Administration of the Property of Such Patients'. In contrast to the old Mental Patients Law, the emphasis in the 1997-2007 law shifted from a custodial approach to the protection of patients' human rights. There is additionally a law enacted in 2005 that safeguards and protects patients' rights.

A designated body, the Mental Health Commission (MHC), a supervisory committee for the protection of the rights of mentally ill people, assists in the correct implementation of the Mental Health Law. The MHC has a primarily advisory role, but it is actively involved in monitoring the implementation of the Mental Health Law. The committee members, appointed by the Council of Ministers for a 4-year term, consist of a psychiatrist, an independent lawyer, and a representative of the Attorney General (an independent officer under the Constitution), the Voluntary Mental Health Organisations, the Psychologists' Association, the Pancyprian Nurses' Association and the Social Workers' Association. 
Key duties of the MHC are to:

(a) review and monitor the application of the Psychiatric Care Law and propose reforms as appropriate

(b) inspect in-patient and out-patient psychiatric centres and advise the Minister of Health in connection with the approval or revocation of their operating licence

(c) investigate all complaints by patients and their relatives and make the necessary recommendations to the Minister of Health.

\section{Mental disorder as defined in law and grounds for compulsory admission}

The 1997 Mental Health Law (MHA) defines 'mental disorder' as 'a disorder of behaviour due to a mental illness (illness of the mind) and is not in keeping with the place, time and age of the individual concerned'.

The mental disorder is considered severe when:

(a) it manifests with violence and serious antisocial behaviour, or

(b) the critical ability (judgement) of the patient has deteriorated to a degree that makes the detainment of the patient necessary for the protection of themselves and/ or those in the vicinity.

The above criteria for 'severe mental disorder' constitute the grounds for compulsory admission. The law makes it clear that violence and antisocial behaviour are considered a mental disorder only if associated with a 'mental illness'.

\section{Procedures for compulsory admission}

According to the Psychiatric Care Law 1997-2007, psychiatric care is only available in registered psychiatric centres, in both the public and the private sector. These have been declared and licensed to operate as such by the Ministry of Health. These centres are:

(a) open psychiatric centres, which offer inpatient treatment to non-violent patients, mostly on an informal voluntary basis

(b) secure psychiatric centres, which provide in-patient care to people requiring compulsory admission.

\section{Open psychiatric centres}

Admission to an open psychiatric centre requires the patient's written consent. Voluntary admission lasts for up to 2 months and can be extended with the written consent of the patient. The MHC is notified as soon as possible.

Individuals with mental disorder who refuse consent may be admitted without an application under the MHA for up to $72 \mathrm{~h}$, on the recommendation of two doctors, at least one of whom should be a psychiatrist. The MHC needs to be immediately notified

If after $72 \mathrm{~h}$ the patient is deemed in need of a continued hospital stay but still refuses to consent to this, the procedure for compulsory care is activated for admission to a secure centre.

\section{Secure psychiatric centres}

Admission to a secure psychiatric centre requires a court order following an application by the individual's personal representative, the police or a social worker, together with psychiatric evidence. A police officer may arrest a person breaching the peace if they have reasonable suspicion that the person may be mentally ill, and may transport them to a safe place where they can be examined and receive treatment for up to $24 \mathrm{~h}$. If appropriate, the procedure for a court order may be initiated.

If a person refuses to submit to examination, this may be carried out after obtaining a 'court order for examination' following the same procedure.

\section{Admission procedures and duration of compulsory admission}

(a) The patient has the right to be heard before the court and to be accompanied by a psychiatrist and lawyer of their own choice.

(b) The compulsory admission court order calls for a temporary period of 28 days for evaluation and treatment, which is followed by re-evaluations every 2 months for a maximum of 12 months. Prior to issue of each order for compulsory order or extension, the court hears from the patient, unless it is satisfied by the evidence supplied that the patient lacks capacity; in this case, the patient's personal representative is heard instead.

\section{Personal representative}

A personal representative, according to the Psychiatric Care Law, is the patient's next of kin or a guardian. The court appoints the latter in the absence of a next of kin. They have a specified role and duration, which can be terminated by the court at any time for good reason.

\section{Treatment}

Detained patients can be treated with medication, but electroconvulsive therapy and psychosurgery (the latter is not practised in Cyprus) are not permitted without the patient's consent.

\section{Discharge}

The treating psychiatrist, in consultation with the multidisciplinary team, may convert compulsory care to voluntary care or discharge the patient at any time.

If continuing compulsory care is considered necessary, the patient or their personal representative may make an appeal to the court. If this is upheld, the court may order immediate discharge or limitation of stay to 2 months or a shorter period. Any court decision may be appealed against at the Supreme Court, which hears and determines all appeals from inferior courts in civil and criminal 
matters. The Supreme Court may uphold, vary, set aside or order the retrial of the case as it deems fit.

According to the law, on discharge, the patient should be provided with community and home services as required. There is, however, no provision for a compulsory community care order.

\section{Discussion}

The law applies to individuals of all ages, and there is no separate provision for minors in the compulsory admission rules. Parents have substantial input in the decision-making for compulsory admission of minors, although the latter is very uncommon. Children and adolescents are admitted to a specific in-patient facility located at a general hospital (the Makarion Hospital) and not the secure psychiatric centre, which does not cater for minors.

With respect to criteria for compulsory admission, it is not made explicit whether such an admission can be considered in the absence of any risk to the safety of the self or others. However, the criterion 'for the protection of self' could be interpreted as meaning the protection of health, preventing deterioration and ensuring well-being. It is not known how often the Act may be used in this way; anecdotally, it appears that doctors prefer not to do so.
Every state hospital is required to appoint a Patient's Rights Officer, and there are designated 'mail boxes' easily accessible to patients and relatives in which to place any complaints, which are collected by a member of the MHC. Leaflets explaining the rights of patients detained under the MHA are made available to them and are also displayed on a wall in all wards, but there is no independent advocacy service other than the above arrangements.

It is not possible to know how the law is applied in practice, as there are no studies as yet specifically examining such issues. Studies are also needed to examine the effectiveness of the supervision by the MHC.

\section{References}

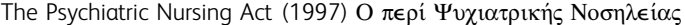
Nómos (N. 77(I)/1997 (Law on Psychiatric Care). House of Representatives; Cyprus.

WHO (2008) Suicide rates by gender and age, Cyprus. http://www. who.int/mental_health/media/cyprus.pdf

WHO (2015) World health rankings 2015. www.worldlifeexpectancy. com/country-health-profile/cyprus

World Bank (2017) World Bank list of economies. databank. worldbank.org/data/download/site-content/CLASS.xls
PSYCHIATRY UNDER RESTRICTIVE CONDITIONS

\title{
Restrictive environments: the challenge of implementing of Brunei's 2014 Mental Health Order
}

\author{
Hilda Ho
}

Ministry of Health, Bandar Seri Begawan, Brunei Darussalam: email hilda.ho@moh.gov.bn

Acknowledgements: I thank Dr Rifai Farid for reviewing the initia drafts of the paper.

Conflicts of interest. The author is Head of Psychiatry at Raja Isteri Pengiran Anak Saleha (RIPAS) Hospital, Ministry of Health, Brunei Darussalam. The views expressed in this paper are her own and do not necessarily represent those held by the Ministry of Health.

doi:10.1192/bji.2017.19
In 2014, Brunei implemented the Mental Health Order, which replaced the 1929 Lunacy Act. This new legislation was designed to improve the treatment of mental disorders and to protect the rights and welfare of people with mental disorders. This short report describes the experience and challenge of implementing the new legislation, with a particular focus on the use of involuntary treatment and the restrictions imposed on people with mental disorders despite the new legislative framework.

Brunei Darussalam is a small country (population 406000 ) in Southeast Asia, which scores highly on economic, health and social indicators (United Nations, 2015). It has a dual legal system consisting of Islamic Syariah law and civil law. Many of its civil laws predate independence and are based on English common law. Healthcare services are predominantly provided by the government free of charge to all citizens and permanent residents.

\section{The aims of the new legislation}

The development, aims and content of the 2014 Mental Health Order (available at http://www. agc.gov.bn) have been described previously (Ho, 2016). One of its main aims was to improve the process of involuntary treatment and to safeguard the patient's rights throughout the process. The guiding principles included the preservation of individual autonomy and the use of 'least restrictive' treatment options, while acting in the best interests of patients. Statutory reviews of involuntary treatment were built in, and an appeals process was introduced. It was hoped that the 